\title{
From Interdisiplinary Interactions Toward Interdisciplinary Knowledge
}

\author{
Oleg N. Yanitsky \\ Ph.D., Professor, Chief Researcher, Federal Center of Theoretical and \\ Applied Sociology of the Russian Academy of Sciences, Moscow, Russia.
}

\begin{abstract}
The article presents a set of arguments on favor of an interdisciplinary approach to any events and transformations of the global SBT-system. Drawing on my previous social experience, the analysis of relevant scientific literature and my own studies on the emergence and development of current pandemics I came to the following conclusions. First, every social or natural action has an interdisciplinary character. Second, the regularities of global SBT-structure development and its feedbacks in relation to global economic and social life are still ill studied. Third, the key moment of any natural and social transformation and the interdisciplinary collaboration are the metabolic processes between qualitatively different essences. Four, the above changes points to the fact that the $X X$ century and further has transformed a scientific thought and knowledge into the planetary phenomena. Five, it's reflects that under current conditions all are interrelated with all. Six, the interdisciplinary approach to an SBT-system of any scale and mode of development has become absolutely necessary. Seven, the emergence and quick spread the pandemics across the world I call as the global critical situation, and it means that the global SBT-system has become over-integrated.
\end{abstract}

Keywords: critical situation, globalization, global SBT-system, interdisciplinary approach, knowledge, metabolic processes, pandemics, time

\section{INTRODUCTION}

Every social action, an environmental transformation and their relationships have an interdisciplinary character. And the metabolic processes i.e. the qualitative transformation of a particular social organism, matter and energy, are the key moments in such interactions and transformations. Therefore, we may state that our life and social activity are the endless metabolic process.

Such great scientists and social thinkers as Vl. Vernadsky have argued that a scientific thought and knowledge are the planetary phenomena. But to reflect adequately, the researcher has to be in the midst of social and natural life (Vernadsky, 1977). Indeed, if we take any natural, social and construction process and the interactions between them we'll see that they are always have the qualitatively transformable character with endless process of metabolic changes of different kind, scale and results. 
Yanitsky, O. N. (2020) A Comparative From Interdisiplinary Interactions Toward Interdisciplinary Knowledge. Advances in Social Sciences Research Journal, 7(5) 359-368.

The current pandemics i.e. the ongoing global critical situation (hereafter the CS) which has generated various transformations in all spheres of our life showed us once again that the numerous metabolic transformations are inseparable part of the global processes. From this viewpoint, the environment in which we live in has represented an inseparable number of metabolic transformations.

\section{SOME HISTORICAL LESSONS}

To my mind, the historical processes, their investigations reflection in the scientific concepts as well as in the archives and other sources of gaining knowledge of the past clearly showed their interdisciplinary character. My father graduated from the Historical faculty of the St. Vladimir University in Kiev (Ukraine) in the year of the 1917 had written his diploma work on the economic crisis in the Great Novgorod in the XVI century (Yanitsky N., 2007). It's rather interesting that this work fully confirms my concept that any historical science is based on the original archival documents that have not only the detailed description of individual urban and rural economies but about their spatial, time and qualitative dynamics. In comparison with recent statistics the archives of the XVI-XVII centuries contained a very interesting and detailed data concerning the dynamics of the economies under consideration.

Such dynamics may be interpreted as various metabolic transformations generated by the interactions of qualitatively different factors as unusual cold weather, crop failure, and starvation. The methodology of this study has been focused on the interactions of numerous short-term and long-term factors of natural and social origin.

It's rather interesting that already in the year of 1924, that is ten years later the other Russian scientists and historians A. Chizhevsky $(1924,1976)$ confirmed that such crisis as happened in the Great Novgorod in the XVI century might be provoked by the periodical fluctuations of the intensity of the Sun rays.

In sum, if we open any fundamental historical research including that of related to the change of civilizations we find out that a physical and social factors of any historical process are highly interdependent. And it cannot be otherwise because humanity for a long time has used the natural processes and instruments for its own needs.

In turn, it means that the processes of development of science as the knowledge and social institution are highly dependent on the goals and types of human activity.

\section{FROM THE INTERDISCIPLINARY INTERACTIONS TO AN INTERDISCIPLINARY KNOWLEDGE}

Let me begin from some general statements formulated by Russian scientist Vl. Vernadsky. He argued that the man for the first time in his history really realized that he is an inhabitant of our planet, and therefore should to think and act not only in the aspect of a separate personality, family or clan, the states and their alliances but in the planetary scale as well. But more exactly, in the biosphere mode of thinking which he uninterruptedly changed (Vernadsky, 1977: 24). Vernadsky called his science as the biogeochemistry, and underscored that this complex scientific discipline is developing by the growth of human needs. 
The usual result of the interdisciplinary interactions is a kind of construction i.e. something built by joint human efforts which I conditionally label as a hybrid. A car or an aircraft are the typical examples. A distinguishing feature of any hybrid is its complexity that it's able to work as a whole but strictly speaking it's not an organism with numerous metabolic processes, i.e. mutual qualitative transformations.

Then, there are some necessary definitions and clarifications related to the abovementioned historical transition. I offer to distinguish the following periods of it. I've realized that it's a hypothesis only but I consider it useful for the understanding of current interdisciplinary processes and transformations.

\section{The first one}

I has named as a craft during which a man combining several forms or methods of his activity without a specific mental reflection called science. The guild had been the main instrument of accumulation and translation to the next generation. A special social institution for such transmission of accumulated guild knowledge hadn't yet existed. To some degree the transmission function of guild crafts had been implemented by the church chroniclers.

\section{The second one}

It had emerged in the Enlightenment epoch in which a scientific knowledge had appeared as a result of accumulation of empirical data in various spheres of human interest, say, in the astronomy, medicine, historical sciences and some others. That epoch has been marked by the establishment of the universities in Europe which served as the institutions for the transmission of accumulated knowledge to the next generations. To my mind, the emergence of so-called empirically-obtained interdisciplinary knowledge has been a main distinguishing feature of the Enlightenment. But initially it has been mainly a knowledge related to structural interdependence of various natural and social entities without the investigation of the metabolic processes between them.

\section{The third one}

This had been the period of the shaping of an evolutionary theory of life processes on the earth. One of its important features had been both the intraspecific and interspecific struggles (Charles Darwin). This point is fundamental to the development of interdisciplinary approach because these struggles are usually accompanied with multiplicity of metabolic transformations. Of course, the geological and biogeochemical processes and transformations as well as the shaping of human communities burdened with social and political transformations should be taken into account.

\section{The fourth one}

Is the biosphere concept developed by Vl. Vernadsky. According to him, the biosphere is a living global whole in which all species including humanity are in the process of permanent interaction and mutual transformation. The life of the biosphere is accompanied with permanent turnover of a matter and energy. To my mind, the biosphere concept is the concept of living organism allembraced by various metabolic transformations of natural, social and geopolitical character. Vernadsky has often mentioned the term of metabolism but never used it in the process of the biosphere development. Implicitly the metabolic idea is presented in the concept of the noosphere (Teilhiard de Shardin) but never developed by him. 
Yanitsky, O. N. (2020) A Comparative From Interdisiplinary Interactions Toward Interdisciplinary Knowledge. Advances in Social Sciences Research Journal, 7(5) 359-368.

\section{The fifth one}

Is my concept of the sociobiotechnisphere (hereafter the SBT-system) (Yanitsky, 2016). The introduction of this concept is defined by two interrelated reasons. The former is substantiated by a permanently growing pressure of humanity activity on the biosphere living organism. The latter is related to the multiplicity of the feedbacks between the global SBT-system and its minor social, natural and built structures. Such double interdependence urges me to move fourth the idea that the global SBT-system is built of many metabolic processes many of which are still not only investigated but even not identified.

This statement is confirmed by the fact that humanity is still not capable to predict them and therefore, as U. Beck rightly stated, is lived in the world of the side-effects of already happened transformations including new critical situation (hereafter the CS). The COVID-19 pandemics and reaction on it of global human community are the best examples.

Thus, voluntary or involuntary the development of natural and social sciences is moved from the monodisciplinary knowledge to an interdisciplinary one. And this shift is quite natural because if we want to surmount our long-term adherence to the studies of the side-effects of already happened transformations we're obliged to learn to make predictions and to build scenarios based on interdisciplinary knowledge.

\section{The first one}

\section{THE ARCHETYPES OF STRUCTURE OF INTERDISCIPLINARY KNOWLEDGE}

Among them is an overt interdisciplinary knowledge. The matter is that in the process of evolution of various sciences and every branch of it borrowed in one way or another some approaches or methods from other sciences and then adapting them to their own needs. As the result, a particular discipline has enriched its theoretical apparatus. The term 'system' is the simplest example which doesn't necessarily means that a certain subject matter actually has a systemic character. Anyhow, it has been significant both to the researchers and pupils. Besides, the very term system has become current in the language of this particular discipline and finally has become into common use and then to the any discipline. It doesn't exclude the case of a direct influence of a particular science language on the common one, and vice versa.

\section{The second one}

Is a kind of collaboration of two different disciplines, for example of the medicine and a kind of engineering one in order to construct a certain biodegradable material in order to rehabilitate an ill person. But as it happened in the previous case, this particular case, if it will successfully ended, may be then spread to the other disciplines and branches of the engineering. Such partial collaboration is usually happened between one or two scientific disciplines and with abovementioned medicine or any other branch of the practice in order to resolve a particular problem.

\section{The third one}

Is a kind of collaboration which I've labelled as a hybridization one. It may be tens of collaborators who involved in a certain constructive process. Let me take as example a construction of an aircraft. The thousands of its constructive elements should be fit one another in maximum degree, and only in this case the aircraft model will present a wholeness which then should be tested in various flight 
regimes. In other words, in this case we see the combination of the hybridization principle and its practical testing.

\section{The fourth one}

Namely a transdisciplinary research and developments from time to time has been mentioned in scientific literature, but I couldn't find its methodological explication except a general statement that the transdisciplinarity is the meta-methodology allowed us to go beyond the particular disciplines. If it's going on about an interdisciplinary research, and it's simply another word that signified it, there are no questions. But it cannot be the only one science because it never could fit and to reflect adequately to the challenges of a diversity of the actors and environments, namely the SBT-systems of various structures with different composition, scale and so on and so forth. I don't understand how it's possible to go beyond the particular disciplines. If we go 'beyond' them it will mean the negation of a qualitative diversity of the global SBT-system or of its parts (Sommervill and Rapport, eds. 2000). But the qualitative diversity of the species and king of their environments is a necessary prerequisite of the existence of the global SBT-system. It's like the same if I will analyze humanity as a homogeneous mass of people without any qualitative differences inherent them.

\section{THE GLOBAL SBT-EVOLUTION UNDER CONDITIONS OF THE CS}

Up to now we implicitly suggested that our analysis is related to the case of normal evolution of global SBT-system. Under 'normal' I mean a more or less interdepended evolution of its biological, social and built parts. In other words, I mean a coordinated changes and developments and wellgoverned of the interrelations of these parts.

But two world wars, the Spanish flu and some other factors clearly showed that the relationships between the above parts may be violated by the various CSs, and one of them is current pandemics generated by the quick global spread of the COVID-19 virus coupled with whether sharp fluctuations, continued mass migration from the Near East and the North Africa to the EU, and the geopolitical tension between the US and China. Besides, the current CS is aggravated by the sharp drop of the gasoil prices. In sum, for the first time in human history humanity has encountered with the CS of a high complexity and with unknown of a more or less safe way out of it. It's quite natural that world's political-economic system hasn't been prepared to the global CS of such complexity.

Let's start our analysis from a simplest scheme of the social consequences of any CS. It's the following: the certain $\mathrm{CS}-\mathrm{a}$ violation of existed balance between the means of production and consumption-a shrinking a labor market-unemployment-an exhausting of personal stocksrapid growth of dissatisfaction-mass protest actions. But it's the simplest scheme while recently it's often complicated by earlier unknown factors and forces. Thus, recently we are usually dealing with nonlinear development of the CSs.

Then, such nonlinear development of the CS usually has its own tempo-rhythms, and their components are usually have own tempo-rhythms as well. After then, a spatial spread of the CS and its after-effects have their own timing dependent on the specificity of natural or built landscape. Besides, such transboundary projects as the 'One Belt-One Road' will have unknown postponed after-effects that mainly depends on local complex environmental conditions, including the social ones violated by such giant projects. We should remember that such after-effects may be immediate or postponed for years. 
Yanitsky, O. N. (2020) A Comparative From Interdisiplinary Interactions Toward Interdisciplinary Knowledge. Advances in Social Sciences Research Journal, 7(5) 359-368.

The question arises: what has to be done for the first time? There are two polar answers to this question. The first one is to follow the CS development. It's well historically-known answer. Of course, various predictions had been done and preventive measures have been taken but when the CS actually happened its developments are usually become much more serious, distractive and longterm than it has been predicted.

The other answer is based on the idea that the emergence of the CSs is an indispensable element of the global SBT-system evolution under current conditions. And the main factor which provoked the CS emergence is a competition for the resources and geopolitical domination. The main but is not only one. The matter is that we still didn't know the laws and trends of this global SBT-system because this system is not the only a result of an integrative effect of the interactions of many qualitatively different structures and forces but the SBY-system under consideration has its own laws of development or decay as a whole that in turn exerts an influence of its particular structures and functions. The concepts of the SBT-system and its CS have to take into account that feedback. As concerned to the current COVID-19 pandemics, the way out of it is still very uncertain. My viewpoint is that the world after the pandemics will be quite different from the existing one. The dialectics of the surmounting it will combine the already existed structures and functions and the new ones. I foresee that a short period of sharp growth of offline communication it will be replaced by a long period of the online one for the following reasons: quick communication, it doesn't require the travel expenses, and new opportunities for the gaining necessary information before a decisionmaking and practical economic or political actions. The task of saving of the energy or the other natural resources, the natural or social ones, came to the forefront (Haberl et al., 2016). But the global scientists have been guilty as well because their long-term investigations aimed at defining the 'limits to growth' of the planet and its population haven't take into account the case of global pandemics (Meadows et al., 1973, 1989; Von Weizsäcker and Wijkman, 2018).

At the same time I've to underscore that the current CS rapidly enhanced the transformations as itself. Usually the most spread reaction is the administrative measures aimed first of all at minimization of human contacts. It signifies that modern global community has no other instruments for the struggle against the spread of the areal of its destructive activity. But at the same time it means that the global community has no other means for the struggle against the pandemics except administrative measures, i.e. the self-isolation ones. At the same time it means that there was neither necessary vaccine nor the other social instruments for a self-organization and protection of local population.

\section{THE PANDEMICS COINCIDED WITH GLOBAL ECONOMIC CRISES}

I consider this coincidence as the testing ground for the understanding the possible ways for transition toward a shaping of interdisciplinary knowledge related to such critical situation. To make the detailed estimations of the shortcomings of current state of matters in the study of such CS is too early. To my mind, an attempt to analyze the interdependence of the biological, economic, social and other factors within this CS will be much more fruitful.

Firstly, I'll fix that economic and geopolitical tension in the world and especially between the US and China has begun much earlier. Sone analytics have stated that the COVID-19 attacks has been a response of China to the accusations from the side of the US. I don't have the necessary information to make such judgments. But under modern conditions such 'response' might be possible in 
principle. In the modern world tightly interdependent by a variety of the resources, goods, logistics, information flows and other forms of mutual interest it might be possible.

Secondly, the COVID-19 pandemics have emerged in China under current conditions of a high spatial mobility of people and species. Therefore, there are still no efficient means to resist to this allembracing and all-penetrating flow of various carriers of any infections. It signifies that any threat or challenge which has emerged in one part of the globe is potentially risky anywhere. This phenomenon is one of distinguishing features of a current phase of globalization.

Thirdly, the modern economic crisis has the same all-embracing and all-penetrating character. Earlier, we may say that such crisis may be localized in one or another part of the world. Recently the local consequences of global economic crisis are the questions of time.

Fourthly, this crisis coupled with the negative outcomes of the pandemics provoked a long chain of negative after-effects of that double risk, and they are potentially used to enhance each other.

\section{THE RELATIONSHIPS BETWEEN AN INTERDISCIPLINARY APPROACH AND TEACHING}

A transmission of new knowledge into the secondary and higher schools is the key issue here. The writing of the text-books plus the lessons or lectures has been the old and mutually accepted means to do it. Accordingly, the corps of selected professionals, pedagogical institutes and the editorial houses has been a solid institutional base for the preparation of such materials. In sum, the process of such transmission took usually from 5-7 till 10-15 years, i.e. it might be written for one generation but really has been used by the next one.

Besides, during the last 50 years the process of generation of the new knowledges and their interrelationships permanently accelerated but the secondary and higher schools lags behind more and more. That is why the regular education process has more and more combined with the school of the Olympics competition and other means of additional teaching and testing. Accordingly, the further the more the fundamental textbooks are losing their significance as the basement of the educational processes whereas the teenagers' and students' involvement into the resolving of practical issues is rapidly growing.

This involvement the youth into resolving the practical issues has one more positive effect, the young has got the practical experience on how the new knowledge including the interdisciplinary one is simplified and transformed in accordance with the interests of a bureaucracy of various scale. And it's quite understandable because the bureaucracy is interested in the conversion of new interdisciplinary knowledge into very simple and not changeable norms and rules. This negative effect of such transformation or more exactly simplification has been analyzed by M. Burawoy in details *(Burawoy, 2008, 2015). Let me mention that after the graduation from the secondary or higher schools any young person is forced to master some additional (practical) knowledge in accordance with the specificity of a particular enterprise, institute or shopping center. It often means that an overwhelming majority of already gained knowledges have become useless i.e. they are transforming into a wasted years of education and individual life.

The educational process isn't equal the process of a creation of the new knowledge. In the best case this process is a kind of the ABC knowledge. For example, the current educational processes never 
Yanitsky, O. N. (2020) A Comparative From Interdisiplinary Interactions Toward Interdisciplinary Knowledge. Advances in Social Sciences Research Journal, 7(5) 359-368.

explain to the pupils what the metabolic processes means and why they are so necessary for the making of the any model of a living organism, be it human species or natural ecosystem. Therefore, the schoolchildren who spend about 3-5 hours in the Internet everyday are much more educated and well-prepared to a further life than their teachers.

Finally, the processes of cognition (epistemology) aren't equal to the processes of education. The cognition is a travelling in the unknown and sometimes very dangerous world. Unfortunately, the majority of research institutes and corporations are inclining to use mass surveys which in turn are mainly using an arithmetic comparisons like 'more or less' 'closer or farther', etc. The epistemology processes are usually investigated not simple i.e. direct relationships but the further the more a nonlinear processes and mobile i.e. transformative strictures. The nonlinear, that is probable movements and transformations and interdependences (see, for example, the works of Chizhevsky, 1924,1976 ) has been and are still now on of the subject matters of modern sciences.

\section{THE COMPLEXITY OF THE PANDEMICS AND GLOBAL ECONOMIC CRISIS}

This complexity once more confirms the maxim of the US biologist B. Commoner: all interrelated with all, al is going somewhere, and the anything is given for nothing. And such interdependence of all with all is in hundred percent peculiar to the current global situation. The economists are still guessing what has been the first, but now it doesn't matter. The combination of the pandemics and global economic crisis gave global cumulative effect, and it is the only one result of such complexity.

Then, that complexity creates a kind of global turmoil that in the final analysis which confirmed my concept of the global SBT-system whose structural-functional organization and regularities of development are still not investigated. It means not only that the studies of global ecosystem conceptualize are still one-sided, that is gives to its development an economic or geopolitical interpretation.

It's a bit surprising to me that even when a global community has encountered with such multisided and inherently interrelated phenomenon as current situation some researchers still discuss what has been the driving force of such all-embracing critical situation. Besides, many economists across the world doesn't see any difference between the economic or geopolitical crisis which are periodically happens, and the critical situation although the definition of the latter has been given in the national and international documents many times.

Of course, the overlapping the pandemics and global economic crisis seriously aggravated the situation in many countries and all over the world. But for us, the sociologists has become clear that our world entered into the period of a succession of various critical situations, and every next one signifies that global community has less and less resources to cope with the next CS.

\section{THE LESSONS OF CURRENT PANDEMICS}

Every step of the scientific and technological development has to be estimated from its impact on all spheres of natural and social life including a global and national politics and decision-making. Their development hand in hand and in common time regime is the best variant. It doesn't mean that that there are no exclusions from this principle and the suddenly-emerged pandemics is the example. The lesson of modern history that a whole world has prepared to already well-known type 
of war suddenly received a mighty strike from the natural world or, as some experts stated, from an artificially-constructed unknown virus hasn't be forgotten.

Then, the pandemics attack has clearly shows that the humanity being well-defended from the rocket attacks, has appeared ill-defended from the biological weapon i.e. from the COVID-19 pandemics. And not only ill-defended having no medicine against it but ill-protected because a necessary infrastructure hasn't been existed at all! In other words, it has been the lesson to any politics in all spheres of human activity, civilian and military.

Another political mistake has been done by those who are involved in various kinds of the geopolitics, locally or globally.

The last but not least argument is related to the science as a social institution. The current pandemics showed how tightly interdependent all spheres of scientific researches. In any case a degree of such interdependence and mutual understanding is possible only in the case when the sphere and instruments of interdisciplinary research is well-developed.

Summing up, I'd argued the following.

Firstly, the global community is in the new transition period. It means that it should be estimated from the viewpoint of all its possible consequences including it structural-functional transformations in space and time. Secondly, the isolation and self-isolation regime it's the forced but not an optimal measure. Thirdly, in particular for the reason that such regime divides a population on those who has smartphones and who has not. Fourthly, such regime is enhanced the division any society on the reach and poor. Fifthly, that regime separates the young and the old because the former have the smartphones and use them permanently while the latter hasn't.

\section{CONCLUSION}

Every social action, an environmental transformation and their relationships have an interdisciplinary character. And the metabolic processes i.e. the qualitative transformation of a particular social organism, matter and energy, are the key moments in such interactions and transformations. Therefore, we may state that our life and social activity are the endless metabolic process burdened or violated by periodical CSs. Every step of the scientific and technological development has to be estimated from their impact on all spheres of natural and social life including a global and national politics and decision-making. Their development hand in hand and in common time regime is the best variant. Therefore, the interdisciplinary approach to an SBT-system of any scale and mode of development is absolutely necessary.

The over-integrated world is a new quality of humanity existence and its further development. That it's now subjected to new challenges and risks first of all generated by the intensive building of a variety of the information structuration of all sides of human life, and it's one more reason for the use of interdisciplinary approach. It is clear that our world entered into the period of a succession of various critical situations, and every next one signifies that global community has less and less resources to cope with the next CS.

\section{References}

Bauman Z. 2017. A Chronicle of Crisis: 2011-2016. London, UK: Social Europe Edition. 163p. 
Yanitsky, O. N. (2020) A Comparative From Interdisiplinary Interactions Toward Interdisciplinary Knowledge. Advances in Social Sciences Research Journal, 7(5) 359-368.

Beck U. 1999. World Risk Society. Malden, MA: Polity Press. 184 pp.

Burawoy M. 2008. What is to be Done? Theses on the Degradation of Social Existence in a Globalizing World. Current Sociology, 56 (3): 351-359.

Burawoy M. 2015. Facing the unequal world. Current Sociology, 63 (1): 5-34.

Chizhevsky A. 1924. Fizicheskie factory istoricheskogo processa [Physical Factors of a Historical Process]. Kaluga: Pervaya Tipolitigraphiya. 121 pp. (In Russ.).

Chizhevsky A. 1976. Zemnoe eho solnechnykh bur' [The Earth Echo of Sun Storms]. Moskva: Mysl' (In Russ.).

Haberl H., Fisher-Kowalski M., Krausmann F. and Winiwater V., eds. 2016. Society-Nature Relations across Time and Space. ISBN (on-line): 978-3-319-33326-7. Available at:

http://link.springer.com/book/10.1007\%2F978-3-319-33326-7

Meadows D.L. and Meadows D. H., eds. 1973. Toward Global Equilibrium. Cambridge, Mass.: Wright-Allen Press.

Meadows D.H., Meadows D. l., Randers J.W. 1989. The Limits to Growth. A Report for the Club of Rome's Project on the Predicament of Mankind. 2nd ed. N.Y.: Universe Books.

Sommervill M. and Rapport D., eds. 2000. Recreating Integrated Knowledge. Oxford, UK: EOLSS Publ. 271 pp.

Vernadsky Vl. 1977. The Thoughts of the Naturalist. A Scientific Thought as a Planetary Phenomenon. Moscow: Nauka Publ. House. Vol 2, 191 pp. (In Russ.).

Von Weizsäcker E.U. and Wijkman A. 2018. Come On! Capitalism, Short-termism, Population, and the Destruction of the Planet. Springer. DOI 10.1007/978-1-4939-7419-1

Yanitsky N. 2007. The Economic Crisis in the Great Novgorod in the XVI Century. Kiev: St. Vladimir University. Reprint Edition. [Compiled and edited by O.N. Yanitsky]. Moscow: TAUS. 169 pp.

Yanitsky 0. 2014. Sociology of Critical Areas. Open Journal of Social Science Research. Vol.2 (3): 112-118. Available at: http://manuscript.sciknow.org/uploads/ojssr/pub/ojssr_140963345.pdf

Yanitsky 0. 2016. Sociobiotechnical systems: a New Approach to Man-Nature Interactions, in: Yanitsky 0. On Globalization and its Environmental Consequences. Moscow: IS RAS' pp. 123-135. Available at:

http://www.isras.ru/index.php?_id1198\&id=4603 